\title{
OPORTUNIDADES DE QUALIFICAÇÃO PROFISSIONAL FATIADAS: AS POLÍTICAS FOCAIS E A FORMAÇÃO DOS TRABALHADORES
}

\author{
Lícia Cristina Araújo da Hora ${ }^{1}$
}

\section{RESUMO}

O artigo analisa a expansão da escola pública, em especial o caso da rede do Instituto Federal do Maranhão. Assim, propõe-se compreender, por meio da análise dos diversos programas de qualificação profissional e de elevação de escolaridade que foram direcionados para formação da classe trabalhadora, o caráter democrático e inclusivo da atual multiplicidade de ofertas formativas que compõem a política educacional dos Institutos Federais. Demonstram-se como as estratégias de inclusão social instituem trajetórias subordinadas de qualificação profissional por meio da diversificação de ofertas educacionais que criam a fantasia do discurso de acesso democrático à escola, intensificando no âmbito destes espaços desigualdade no acesso efetivo e democrático ao conhecimento. Destaca-se ainda como a diversidade de ofertas produz uma formação em fatias, característica de uma concepção de política pública que direciona ações focalizadas às comunidades definidas no discurso oficial como: carentes, pobres, marginalizadas, vulneráveis e de baixa renda. É exposto ainda como a distribuição desigual do conhecimento é organizada como estratégia de formação e de controle da classe trabalhadora.

Palavras-chave: Expansão da educação profissional; Políticas Focais; Trabalho e Educação.

\section{OPPORTUNITIES FOR PROFESSIONAL QUALIFICATION SLICED: FOCAL POLICIES AND TRAINING OF WORKERS}

\begin{abstract}
The article examines the expansion of the public school, in particular the case of the Federal Institute's network of Maranhão. Thus, it is proposed to understand, through the analysis of various programs of professional qualification and lifting of schooling that were targeted to working-class formation, democratic and inclusive character of the current multiplicity of educational offerings that make up the educational policy of the Federal Institutes. Demonstrate itself as social inclusion strategies establish subordinate trajectories of professional qualification through the diversification of educational offerings that create the fantasy of the speech of democratic access to school, stepping up within these spaces unequal access effective and democratic knowledge. Still stands out as the diversity of offerings produces a formation in slices, characteristic of a conception of public policy which directs actions targeted to communities defined in the official discourse as: marginalized, poor, needy, vulnerable and low income. Is exposed as the uneven distribution of knowledge is organized as a strategy of training and control of the working class.
\end{abstract}

Keywords: Expansion of vocational education; Focal policies; Work and Education. 


\section{A EXPANSÃO DA ESCOLA PÚBLICA EM FATIAS PARA OS POBRES}

Ao longo da história de expansão da escola pública no Brasil, duas marcas expressam sua constituição: a primeira refere-se ao caráter político-econômico, presente em todos os processos para criação e ofertas de matrículas, ora para atender a demanda produtiva, ora para atenuar crises de caráter social, funcionando como controle social em crises agudas do capitalismo. A segunda marca refere-se à dualidade presente na trajetória da expansão escolar, própria da divisão social do trabalho no modo de produção dominante, no qual as tarefas intelectuais cabem àqueles que irão dirigir, e as atividades operacionais são destinadas àqueles que são dirigidos. Para o primeiro grupo, é necessária a oferta escolar de melhor qualidade, por meio do ensino propedêutico; para o segundo são reservados os cursos profissionalizantes com propostas aligeiradas, de curta duração ou os programas sociais estruturados com base na dualidade estrutural de novo tipo.

Nessa perspectiva de expansão escolar, na transição da acumulação fordistataylorista, baseada na acumulação intensiva por meio da produção em massa, desenvolveuse um tipo de trabalhador cuja denominação ficou conhecida por operário-massa ou trabalhador coletivo. $\mathrm{Na}$ acumulação toyotista, este trabalhador coletivo pressupõe a constituição de uma nova subjetividade. Sendo assim, o principal intento do novo regime é: "promover a direção moral-intelectual do capital na produção, articulando consentimento operário e controle do trabalho, capaz de realizar a subsunção do operário à lógica do capital” (ALVES, 2000, p. 159).

Gramsci apresentou inúmeras questões metodológicas revestidas de caráter ideológico-político e histórico, preocupado com a superação do homem-massa em substituição ao homem-coletivo ${ }^{2}$, entre estas encontra-se a mediação entre "a escola humanística e a escola unitária do trabalho, o problema de conciliar o rigor metodológico próprio da fábrica e a abertura mental própria da exigência humanística" (MANACORDA, 1990, p. 67).

A dualidade estrutural na educação efetivou-se de formas diversas em diferentes sociedades, a partir de seus processos históricos e da correlação de forças estabelecidas em diferentes frações de classe. Desse modo, a educação profissional foi, ao longo da história, consolidando-se como "aquela de base prática, voltada para as classes populares, que iriam ocupar os postos de trabalho produtivo na sociedade ou, nas palavras da época, era aquela voltada para os desfavorecidos da fortuna" (BRANDÃO, 1999, p. 2). Por outro lado, aos filhos da burguesia era propiciado estudo de formação propedêutica, erudita, de modo a prepará-los para ocupar os melhores cargos da sociedade, dentre eles os de dirigente, alimentando, assim, a elite dirigente de suas concepções de mundo e promovendo, dessa forma, a reprodução da distribuição desigual do conhecimento e a manutenção da subsunção da produção, do consumo, da cultura e dos papéis políticos e sociais.

Para Kuenzer (1999), a categoria dualidade estrutural demarca uma clivagem à formação de trabalhadores no Brasil e também explicativa para a compreensão histórica das políticas educacionais, sobretudo no que tange à educação profissional. Esta categoria delimita a separação na trajetória educacional dos que irão desempenhar as funções instrumentais e as funções intelectuais, reflexo da separação existente na divisão capital e trabalho, cuja melhor explicação pode ser traduzida no taylorismo-fordismo, no qual se encontra a cisão entre a concepção de atividades de planejamento, supervisão e atividades de execução e práticas do cotidiano do labor.

A marca da visão produtivista da educação, dualista e fragmentária, atravessou o século XIX no Brasil e chegou à segunda década do século XXI sob a roupagem da 
democratização da escola pública por meio de uma multiplicidade de ofertas educativas em diferentes qualidades educacionais.

A expansão escolar no Brasil constitui-se, de fato, com essa marca. A produção de uma escola precária para o atendimento dos segmentos sociais mais pobres, comumente vista como uma "expansão desordenada", é orgânica ao baixo alcance dos projetos inovadores, do fato de que os mesmos, ainda que fossem concebidos para chegar a todos, jamais chegariam, pois seu alcance não dependia da vontade de quem produzia os projetos, mas das relações que formavam a base real da sua implementação. A função real assumida por esses projetos implica que eles se realizem como uma chance para poucos e uma promessa para muitos [...] (ALGEBAILE, 2004, p. 94-95).

Enquanto para Cunha (2005b) a expansão da escola profissionalizante assumiu, além de um caráter econômico, um caráter também político-representativo, para Alves (2006), a escola pública, a partir da década de 1970, desenvolveu-se por meio da expansão das atividades improdutivas por força da ação reguladora do Estado, uma vez que em busca da superação do desemprego estrutural buscou atenuar a crise "mediante a expansão escolar e dos serviços de saúde pública, crescimento do funcionalismo público, ampliação das forças armadas, bem como do incremento às obras públicas" (ALVES, 2006, p. 180).

Desse modo, a escola pública apresenta-se,

Retrógada, por manter uma organização didática anacrônica, e descomprometida com o conhecimento, pelo aviltamento de seus conteúdos curriculares, sua expansão é necessária, do ponto de vista material, pois permite a alocação de trabalhadores expulsos das atividades produtivas junto às camadas intermediárias da sociedade, executoras de atividades improdutivas. Eis o segredo da força irrefreável do processo de expansão da escola pública no final do século XIX e ao longo século XX (ALVES, 2006, p. 184).

$\mathrm{O}$ argumento apresentado por Cunha (2005b) possibilita-nos compreender que o processo de expansão da educação profissional no Brasil não esteve somente atrelado ao determinante econômico, mas também ao caráter político e, isto, sem dúvida, até hoje encontra-se perceptível na expansão dos Institutos Federais ${ }^{3}$, quando da escolha dos municípios para implantação dos Campi. No Maranhão, por exemplo, está marca é acentuadamente presente. Nesse sentido, a análise de Alves (2006) amplia este entendimento, demonstrando o caráter estratégico que persegue a expansão da escola pública ao longo da história, marca importante para analisar com afinco a dualidade estrutural de novo tipo ${ }^{4}$.

Acentuada como marca do conjunto de ações educacionais do governo Luís Inácio Lula da Silva, a partir dos anos 2000, a dualidade estrutural de novo tipo refere-se a um cenário de mudanças no processo de democratização da escola e

[...] se expressa entre outros aspectos, nas distinções entre as redes municipais, estaduais e federais, e, no seu interior, entre vários modelos e modalidades; nos variados padrões de oferta das redes privadas; na multiplicidade de "oportunidades formativas" que recriam ou instituem trajetórias subordinadas de formação, as quais, em conjunto, ressignificam a marca social da escola, cujo caráter classista é encoberto 
pelo discurso "inclusivo" (RUMMERT; ALGEBAILE; VENTURA, 2012, p. 42).

A dualidade estrutural de novo tipo é a expressão mais veemente de que a democratização da escola pública tem ocorrido tão somente pela ampliação quantitativa de escolas, pois da distinção na forma de acesso ao conhecimento e na obtenção da certificação, "obscurecem assim, cada vez mais, o fato de que não há, efetivamente, ações destinadas à elevação igualitária do nível educacional da classe trabalhadora em sua totalidade" (RUMMERT; ALGEBAILE; VENTURA, 2012, p. 39).

Desse modo, a questão primordial não recai somente na problemática da qualificação profissional dos trabalhadores, mas, sobretudo, na forma como o conhecimento é viabilizado no interior da escola, de modo que seja possível, por parte da classe trabalhadora, compreender a dinâmica da sociedade capitalista. De acordo com Alves (2006), são os conhecimentos fundamentais, tais como o científico e o humanístico, que facultam ao trabalhador o entendimento acerca do próprio fazer no todo social. "Logo, não se advoga, sob hipótese nenhuma, a ideia de requalificação dos trabalhadores porque as condições objetivas da produção capitalista estão dispostas no sentido de incorporar trabalho simples" (ALVES, 2006, p. 150).

Segundo Rummert, Algebaile e Ventura (2012) a variação de ofertas educacionais em formas desiguais e combinadas produz uma miríade de ofertas de elevação de escolaridade/formação profissional/certificação que fortalecem as ações da pedagogia do capital-imperialismo por meio da "fantasia de que a efetiva democracia chegou à educação escolar". Caracterizadas e divididas entre os mais diversos programas, sejam de qualificação/escolarização social, a diversidade de ofertas formativas produz vias subordinadas de acesso à escola conforme as classes sociais.

Na perspectiva apontada pelas autoras, na qual faz-se alusão no título deste artigo, a diversidade de ofertas produz uma formação em fatias, característica de uma concepção de política pública que direciona ações focalizadas às comunidades definidas no discurso oficial como: carentes, pobres, marginalizadas, vulneráveis e de baixa renda. Esta relação é melhor definida por Algebaile (2004, p. 117) que ao tratar acerca da expansão da escola pública e a distinção da formação para os pobres, reforça a ideia de que o Estado garante uma espécie de contra-peso a favor dos "menos favorecidos".

Assim, a marca fundamental da dualidade estrutural de novo tipo é a produção de uma multiplicidade de oportunidades formativas, porém de forma subordinada, garantindo o acesso à escola pelos fundos a um tipo de ensino voltado aos trabalhadores, e o acesso pela frente ao ensino socialmente referenciado, destinado a um público distinto de aluno.

De acordo com as autoras (ibidem), a dualidade estrutural de novo tipo organiza-se em três grandes grupos que compõem uma variada forma de oferta educacional: $01^{\circ}$ grupo diz respeito a programas dirigidos à ampliação do ingresso, reinserção, permanência e conclusão da escolarização regular obrigatória; o $2^{\circ}$ grupo refere-se a cursos e programas dirigidos à ampliação da escolaridade de jovens e adultos e; finalmente o $3^{\circ}$ agrupamento é constituído por programas de financiamento educacional que vêm influenciando significativamente na expansão de vagas e na multiplicidade de vias formativas no Ensino Médio, na educação profissional e no Ensino Superior. Esta análise pode ser melhor visualizada no quadro a seguir em que se expressa a diversidade de ofertas formativas do Instituto Federal do Maranhão: 
Quadro 1 - Diversidade de ofertas formativas para os trabalhadores no IFMA

PROGRAMAS

Mulheres Mil
PARCERIAS $^{5}$

SETEC/MEC,IFs, Canadá

\section{PÚBLICO ALVO}

Mulheres de baixa renda, vulneráveis socialmente e de baixo nível de escolaridade; moradoras de comunidades integrantes dos Territórios da Cidadania e/ou com baixo índice de desenvolvimento humano.

Jovens e adultos para atuarem na Indústria de Petróleo, Gás, Energia e Biocombustível.

Jovens e adultos que procuram carreira técnica e desejam trabalhar nas áreas operacionais.

\begin{tabular}{cll}
\hline PROMIMP & Petrobrás & \\
\hline PRONATEC & & $\begin{array}{l}\text { Jovens e adultos entre 16 e 59 anos } \\
\text { cadastrados em situação de extrema } \\
\text { pobreza ou beneficiários do Bolsa } \\
\text { Família e do BPC }\end{array}$ \\
& MEC, Ifs & \\
\hline
\end{tabular}

\begin{tabular}{ccl}
\hline PROCAMPO & SECADI/MEC & $\begin{array}{l}\text { Educadores que atuam na educação } \\
\text { básica do campo e que não possuem } \\
\text { formação de nível superior em } \\
\text { Licenciatura Plena. }\end{array}$ \\
\hline $\begin{array}{c}\text { Programa Saberes da Terra - Brasil } \\
\text { Alfabetizado }\end{array}$ & SECADI/MEC & $\begin{array}{l}\text { Educadores de educação básica; } \\
\text { educadores de qualificação } \\
\text { profissional. }\end{array}$ \\
\hline PROEJA & SETEC/MEC & Egressos do ensino fundamental. \\
\hline PROEJA - FIC & SETEC/MEC & $\begin{array}{l}\text { Egressos do Sistema Prisional de São } \\
\text { Luís-MA }\end{array}$ \\
\hline $\begin{array}{c}\text { Projeto de Formação Continuada } \\
\text { PROJOVEM Campo/Saberes da } \\
\text { Terra }\end{array}$ & $\begin{array}{l}\text { Educadores de educação básica; } \\
\text { educadores de qualificação } \\
\text { coordenadores de turma que atuarão } \\
\text { no Projovem Campo no estado do } \\
\text { Maranhão. }\end{array}$ \\
\hline E-TEC Brasil & SECADI/MEC & Egressos do ensino fundamental. \\
\hline UAB & SETEC/MEC & Egresso do ensino médio. \\
\hline PARFOR & SESU/MEC & $\begin{array}{l}\text { Professores em exercício das escolas } \\
\text { públicas estaduais e municipais sem } \\
\text { formação adequada. }\end{array}$ \\
\hline
\end{tabular}

Fonte: Pró-Reitoria de Ensino (PROEN) e Pró-Reitoria de extensão (PROEX) do IFMA. Quadro elaborado pela autora.

Desse modo, realizamos, por meio de pesquisa documental e de campo, o mapeamento de treze programas até o ano de 2013, cujo atendimento compreendia as mais diferentes classes sociais, no qual a qualidade do ensino diferenciava-se conforme a forma de oferta de programa ou curso.

Esta diferenciação no que tange à qualidade do ensino foi observada na oferta de cursos e programas em aspectos relativos à: mudança do quadro docente e qualificação, organização de conteúdos e carga horária, condições de funcionamento do curso e turno de horário de aulas. Os programas buscavam fundamentalmente atender a jovens e adultos que se encontram em situação de vulnerabilidade social. Sob a promessa de progresso econômico, desenvolvimento local, melhoraria da qualidade de vida, obtenção de emprego, as ofertas educacionais produzem uma ideologização da educação que busca obter "o consentimento ativo dos governados" (GRAMSCI, 1995). 
Nesse cenário, caracterizado por múltiplas ofertas educacionais não somente identificada no IFMA, mas uma característica acentuada em toda Rede Federal de Educação Tecnológica e em todos os níveis de ensino, o PROEJA, o Programa Mulheres Mil, o PRONATEC e o Programa Rede Certific configuraram-se como mais um programa que visa instituir trajetórias subordinadas de formação.

O cenário expresso neste quadro demonstra como a dualidade estrutural se reconfigurou, possibilitando no âmbito da escola pública a reprodução da desigualdade entre as classes sociais.

Desse modo, a análise histórica da expansão da escola pública e da expansão da educação profissional do Governo de Luís Inácio Lula da Silva permite-nos perceber como a dualidade estrutural, no que se refere à formação dos trabalhadores, é recriada por meio de uma diversidade de ofertas formativas e de ações educacionais que constroem um cenário de mudanças e de falseamento da democratização do acesso à escola pública pela via da ampliação das vagas, com oportunidades formativas subordinadas, configurando a dualidade estrutural de novo tipo, conforme analisado por Rummert, Algebaile e Ventura (2012).

Nesse sentido, a política educacional com base na fórmula de mais com menos tem garantido a expansão da escola pública para os filhos dos trabalhadores, porém, de acordo com Algebaile (2004), como uma escola que "cresce para menos", produzindo a fórmula histórica de mais matrículas e menos recursos. Seria, então, uma estratégia de divisão da fatia em migalhas como estratégia de alívio à pobreza por meio da oferta do mínimo necessário à obtenção de governabilidade? Não por acaso, o PRONATEC surgiu como o programa da vez. Vitrine da campanha eleitoral da Presidente Dilma Roussef no ano de 2014, o programa foi apresentado como prioridade para área de educação com a pretensão de criação de 12 milhões de vagas.

O PRONATEC é uma ação de força de chumbo para fortalecer os canhões do sistema $\mathrm{S}$ em relação ao atendimento produtivo dos industriais, além de reunir todas as condições para que se intensifique o processo de reprodução da desigualdade das classes sociais, garantindo ainda: um quadro de trabalhadores para o mercado da informalidade, alívio à pobreza, segurança social, controle social, atenuando conflitos em áreas de extrema pobreza, conformação ideológica pela captura subjetiva do discurso do empreendedorismo, garantia da divisão da formação do trabalho entre simples e complexo nas estruturas organizativas dos cursos e aprofundamento da precarização do trabalho e da formação humana na Rede Federal de Educação Profissional e Tecnológica.

O processo de expansão da educação profissional contingenciada pela fragmentação compulsória da formação da juventude seguiu o compasso do que foi a universalização do ensino fundamental, ou seja, a efetivação do acesso dentro de uma profunda desigualdade intra e entre regiões. A diferenciação e a dualidade dão-se aqui pelo não acesso efetivo e democrático ao conhecimento. A escola pública dos pobres e/ou dos filhos dos trabalhadores, como apresenta a tese de Algebaile (2004), é uma escola que "cresce para menos". Assim,

mesmo sob essas condições de dualidade, o ensino médio se constitui numa ausência socialmente construída, na sua quantidade e qualidade e como o indicador mais claro da opção da formação para o trabalho simples e da não preocupação com as bases da ampliação da produção científica, técnica e tecnológica e o direito de cidadania efetiva em nosso país (FRIGOTTO, 2007, p. 1139). 
Para Fontes (2010), a disseminação das políticas de conta-gotas foi fortalecida no Brasil na década de 1990, quando a intervenção do Banco Mundial nas políticas sociais foram aprofundadas em diferentes políticas: educação, saúde, assistência social. Assim, disseminou-se "um gotejamento de minúsculas migalhas destinadas às famílias mais carentes" (idem, p.297).

Para melhor eficiência e resultados do empresariamento das massas trabalhadoras, torna-se fundamental para o capital ter "o controle e formação dos trabalhadores" (FONTES, 2010, p. 299). Para atingir os resultados estimados, os empresários convocam a pedagogia do capital-imperialismo para "configurar a classe trabalhadora e a própria sensibilidade social nacional para as novas condições psicofísicas da divisão internacional do trabalho, nas quais o Brasil passa a atuar como "parceiro' do capital-imperialismo" (FONTES, 2010, p. 348).

A política do "mais com menos" amplia as condições de acesso diversificando as formas de manutenção da subalternidade das classes empobrecidas, sem, contudo, aprofundar a necessidade de alteração da dinâmica da vida social dos alunos trabalhadores. Portanto, a expansão da escola pública deve considerar a qualificação do trabalho produzido no âmbito destes espaços, garantindo infraestrutura de laboratórios, professores qualificados, formação permanente, salários dignos, carreira estruturada de modo que possibilite trabalho em tempo integral em uma única escola, além da oferta educacional com igualdade de classes.

\section{AS POLÍTICAS FOCAIS E O FORTALECIMENTO DA RELAÇÃO EDUCAÇÃO E EMPRESA}

As políticas públicas dirigidas às primeiras décadas do século $\mathrm{XX}$, período da modernização capitalista conservadora, corroboraram para a formação profissional seletiva, respondendo a uma dupla determinação: "as necessidades de valorização do capital e a busca - de cima para baixo - de um consenso mínimo, no limite de um capitalismo dependente e em estágio inicial de estruturação" (NEVES, 2000, p. 35). Os anos de 1930 e 1940 caracterizaram-se no campo educacional pela associação dos empresários na consolidação do ramo técnico-profissionalizante, criando, conforme destaca Neves (2000), uma organização de cursos voltados para formação do trabalho complexo - o ensino técnico-profissional agrícola, comercial, industrial e normal e cursos voltados para a formação do trabalho simples gerenciado no âmbito do sistema $\mathrm{S}$.

Assim, conforme já foi expressa, a expansão da escola pública tem como marca uma visão produtivista - dualista e fragmentária - que se transveste em diferentes estratégias de modo a promover o discurso da democratização da escola pública por meio de uma multiplicidade de ofertas educativas, demarcando acentuadamente a educação das massas e das elites.

A expansão da Rede Federal de Educação Profissional Tecnológica e o avanço das políticas focais como conjunto das estratégias de convencimento passivo e ativo das massas $^{7}$, conforme observado no Quadro 1, tem garantido o fortalecimento das relações de empresas como a Petrobrás e a Vale com os Institutos Federais, consolidando o "télos competitivo" (RODRIGUES, 1998), ou seja, a incorporação para o interior destas escolas das propostas industriais à formação humana. $\mathrm{O}$ processo de privatização do conhecimento e de mercantilização dessa mercadoria pelas empresas contribuem para o aprofundamento da subsunção real do trabalhador na dinâmica do regime de acumulação flexível e as demandas da valorização do capital. 
Morais (2007, p. 169) pontua que a Vale é uma empresa pioneira no Maranhão na "adoção de Programas de Qualidade Total, atendendo às exigências do mercado internacional". Nas relações entre educação e trabalho, "uma das ideias força que organiza a pedagogia do capital-imperialismo é a pedagogia das competências, tal como apropriada de forma hegemônica" (RUMMERT; ALGEBAILE; VENTURA, 2012, p. 23).

A convocação da pedagogia do capital-imperialismo será feita pelo empresariado, sempre que necessário na história, e a escola pública sob diferentes estratégias atua como parceira fundamental na formação do trabalhador de novo tipo (polivalente, multifuncional e flexível), pois a parceria escola e empresa é estruturante na relação trabalho e educação na ótica capitalista, pois "na ponta do mercado, que exclui para incluir em trabalhos precarizados ao longo das cadeias produtivas, dialeticamente complementada pela inclusão excludente na ponta da escola, que, ao incluir em propostas desiguais e diferenciadas, contribui para a produção e para a justificação da exclusão" (KUENZER, 2007, p. 1.165).

No que se refere às relações imbricadas entre os Institutos Federais, o processo de expansão sob a lógica imperativa de atender os Arranjos Produtivos Locais, cuja concepção oficial significa os arranjos refletidos na produção de empresas (petroleiras, siderúrgicas, mineradoras, de celulose, guseiras, empreiteiras, construtoras, agronegócios etc.), observa-se, conforme Oliveira (2003) que os setores denominados de atrasados, improdutivos e informais se constituem em condição essencial para a modernização e integração da economia firmada na relação dialética que se alimenta de relações novas no arcaico e reproduz relações arcaicas no novo.

No caso do Maranhão, a primeira fase da expansão priorizou o eixo produtivo da estrada de ferro Carajás, região de atuação da Vale e de empresas siderúrgicas produtoras de ferro-gusa. De acordo com dados obtidos no Relatório do Observatório Social (2006), três fatores são determinantes para o crescimento lucrativo no mercado das siderúrgicas: 1) a valorização comercial do ferro-gusa no mercado externo; 2) a forte atuação internacional da CVRD e; 3) a entrada da China no setor.

Conforme perfil das empresas que atuam na região descrita, algumas siderúrgicas estão sob controle de grupos empresariais de construtoras. Sobre estas, Fontes (2010) destaca que Odebrecht, Andrade Gutierrez, Camargo Corrêa, Mendes Junior, Queiroz Galvão e OAS iniciaram seu processo de transnacionalização na década de 1970. O grupo Gerdau que iniciou seus investimentos no Maranhão na década de 1980 é a terceira empresa mais internacionalizada no país.

A Empresa Vale está em sétimo lugar e sua atuação tem capilaridade em diferentes continentes do mundo, atravessando a África do Sul, Alemanha, Angola, Argentina, Austrália, Canadá, Cazaquistão, Chile, China etc., tornando-se a maior empresa de mineração mundial e empregando 29,9 mil trabalhadores no exterior.

Segundo Fontes (2010, p. 346), "a atuação do capital-imperialismo se intensificou nos últimos anos, ela tem origens mais remotas, tanto na expansão das empresas, quanto na configuração de uma política de Estado". Fontes (2010) aponta ainda que o processo de internacionalização das empresas brasileiras vem sendo paulatinamente subsidiado pelo Banco Nacional do Desenvolvimento Econômico e Social (BNDES) desde o governo Sarney (1987-1990). O processo de investimento na internacionalização foi incentivado no governo Lula da Silva, em 2005, quando foi implantada uma linha de crédito para este fim.

De acordo com Fontes (2010, p. 39), o processo de transnacionalização da economia envolve todo o conjunto da vida social, sobretudo dos países de capitalismo periférico. A expansão do capital internacional ou como melhor pode ser nominada, a expansão do capital- -imperialismo "favorece as políticas de alívio por gotejamento a 
determinadas pressões sociais internas, assim como se constitui em novo fator ufanista e obscurecedor das relações de exploração reais, internas e externas".

Conforme destaca Fontes (2010, p.297), a disseminação das políticas de contagotas foi fortalecida no Brasil na década de 1990, quando a intervenção do Banco Mundial nas políticas sociais foram aprofundadas em diferentes políticas: educação, saúde, assistência social. Desse modo, disseminou-se "um gotejamento de minúsculas migalhas destinadas às famílias mais carentes".

Para melhor eficiência e resultados do empresariamento das massas trabalhadoras, torna-se fundamental para o capital ter "o controle e formação dos trabalhadores" (FONTES, 2010, p. 299). Para atingir os resultados estimados, os empresários convocam a pedagogia do capital-imperialismo para "configurar a classe trabalhadora e a própria sensibilidade social nacional para as novas condições psicofísicas da divisão internacional do trabalho, nas quais o Brasil passa a atuar como "parceiro' do capital-imperialismo" (FONTES, 2010, p. 348).

Nesse sentido, a expansão das políticas de gotejamento e as ações da pedagogia do capital-imperialismo, por meio da pedagogia das competências, fazem parte de um conjunto de estratégias envolvidas "com algum tipo de 'projeto social', extremamente reveladoras desse novo quadro geral de oferta educacional que, simultaneamente, expressa e produz novas formas e condições de formação humana em curso" (RUMMERT; ALGEBAILE; VENTURA, 2012, p. 43).

O governo Luís Inácio Lula da Silva apresenta como marca do seu governo a multiplicação de programas que se entrelaçam, estabelecendo dependência entre si, garantindo com efetividade o controle dos trabalhadores nas mais variadas frentes de políticas focalizadas (saúde, habitação, renda, moradia e educação).

As políticas focais alastraram-se no âmbito dos Institutos Federais, conjugando para seu interior o papel de: integração social, empregabilidade e assistencialismo. Estas políticas e os programas de qualificação profissional pela via das trajetórias subordinadas induzem o consenso ativo dos governados e exigência da governabilidade do capital financeiro.

Para José Paulo Netto (2010) uma face mais contemporânea da barbárie no Brasil apresentou-se no governo Lula da Silva por meio da articulação da repressão aos pobres com a minimização dos programas de combate à pobreza. Podemos destacar que a diversidade de programas de elevação da escolaridade e de qualificação profissional para os jovens e adultos trabalhadores inscrevem-se no quadro de programas que compõem, entre outros programas, a face contemporânea da barbárie.

Os programas mapeados no IFMA, em sua maioria presente em todos os Institutos Federais, revelam a face evidente da barbárie. Vários programas direcionam-se para grupos de baixa renda, vulneráveis socialmente, em situação de pobreza extrema e beneficiários da bolsa-família. O PRONATEC é o mais novo programa desta miríade de ofertas, implicando entre inúmeras outras questões no financiamento público da oferta privada de educação profissional por meio da parceria com o Sistema $\mathrm{S}$ e outras organizações privadas; intensificação, precarização, fragmentação e privatização dos profissionais da rede federal de ensino, com concessão de bolsas para adicional de seus salários, desviando o debate sobre a qualidade da carreira docente para o debate da 'compensação da luta individual no atual cenário de precarização desta carreira.

Esse conjunto de programas que institui a dualidade estrutural de novo tipo, compõe, conforme destaca Netto (2010), se expressa exatamente no trato que, nas políticas sociais, nos oito anos do governo Luís Inácio Lula da Silva, foi conferido à questão social. Netto (2010) ressalta ainda que para o pensamento conservador a questão social possui 
características inelimináveis e se torna uma ação moralizadora que no máximo pode ser objeto de uma intervenção política limitada. Fontes (2010) denominou estas intervenções políticas limitadas de políticas de alívio por gotejamento.

O avanço do capital internacional no Maranhão "favorece expansão das políticas de alívio por gotejamento" (FONTES, 2010), neste conjunto, integra-se a diversidade de ofertas formativas do IFMA na região dos Carajás, cujas pressões e conflitos sociais buscam ser atenuados pela disseminação da política de conta-gotas.

A nova institucionalidade política tem como um de seus principais alvos os professores, entretanto não se pode perder de vista como esta nova constitucionalidade alcança o trabalho desenvolvido pelos técnicos em educação. Contudo, é principalmente sobre os professores que recai a tarefa milagrosa de atingir o pacote de metas do MEC para os Institutos Federais: meta de expansão de matrículas nos mais diferentes níveis e modalidades, meta de produção científica, meta de projetos de extensão, meta de captação de recursos, além da acirrada cultura competitiva que se instalou.

Nessa perspectiva, precisamos construir boas experiências para divulgá-las em eventos nacionais, disputar editais para estruturar laboratórios, patentear pesquisas e avançar na produção em caráter de inovação tecnológica, ganhar prêmios, ficar em primeiro lugar no ENEM. A cultura competitiva na nova institucionalidade da rede federal nos possibilita visualizar novos contornos, conforme destaca Mancebo (2010):

[...] assistimos aos novos contornos que se desenham para o capitalismo nas sociedades contemporâneas, a uma produção maleável e individualizada, à valorização dos trabalhadores qualificados polivalentes, à flexibilização da organização do trabalho, à implementação de horários indefinidos de trabalho e à precarização dos vínculos trabalhistas, também presenciamos a convocação irrestrita da subjetividade do trabalhador para o centro dos processos de trabalho, não raramente com aumento do sofrimento subjetivo, neutralização da mobilização coletiva e aprofundamento do individualismo. Nas escolas, é gerada uma "sociedade da urgência", que força o incremento das tarefas, a instalação de horários atípicos, a aceleração no desempenho das atividades e que afeta em cheio a produção docente, sua subjetividade e saúde.

Uma das faces perversas da cultura competitiva inclui ainda a importância de ocuparmos o ranking dos melhores, ainda que as condições estruturais para organização do trabalho pedagógico concorram para nos colocarem no mesmo ranking de um amplo cenário de precarização e intensificação configurada na nova morfologia do trabalho na rede federal.

\section{A FORMAÇÃO PARA INCORPORAÇÃO DO TRABALHO SIMPLES E PARA O CONTROLE DA CLASSE}

O processo de expansão e ofertas de cursos dos Institutos Federais é apresentado em documentos oficiais que versam sobre a nova institucionalidade da rede federal sobre a necessidade de atendimento aos Arranjos Produtivos Locais - APLs. Assim, analisamos as ofertas de cursos na primeira etapa da expansão, buscando compreender como é definida e organizada a formação para os pobres por meio de políticas públicas focalizadas. Nesta perspectiva, fizemos o recorte desta análise direcionada especificamente a um programa, o PROEJA, considerando que este é direcionado a jovens e adultos em idade socialmente 
irregular e conforme o discurso oficial é um público cujo perfil socioeconômico se define como: carentes, pobres, marginalizadas, vulneráveis e de baixa renda.

Entender a dinâmica desenvolvida na relação entre as ofertas educacionais e os arranjos produtivos locais nos possibilita perceber a partir da relação trabalho e educação que a formação para os pobres é melhor compreendida quando incorporamos na análise a categoria classe trabalhadora, pois conforme destaca Rummert (2007) a distribuição desigual de oportunidades educacionais continua a ser uma questão derivada da origem socioeconômica e das assimetrias de poder daí advindas. Trata-se, portanto, de uma questão de classe e da formação da classe trabalhadora.

Para entender as relações anteriormente destacadas é importante que os Arranjos produtivos locais se caracterizam por aglomerações territoriais de agentes políticos, econômicos e sociais, e este conjunto possibilita, segundo Erber (2008), ganhos de eficiência que os agentes individualmente não obteriam sem a eficiência coletiva; é neste ponto que se situa a vantagem competitiva. Conforme destaca o autor, buscando apresentar uma síntese, a vantagem competitiva tem como base a eficiência coletiva, em economias externas e ação conjunta.

Erber (2008) aponta que a perspectiva de APLs no âmbito da REDESIST, consequentemente no âmbito do MEC, do Ministério do Desenvolvimento e no SEBRAE, relaciona-se a APLs industriais, ou seja, a uma política industrial. Sendo assim, a abordagem teórica que fundamenta estes APLs é a teoria da organização industrial, cuja unidade de análise é a indústria; a natureza da vantagem competitiva é sustentável, fundada no exercício de situações de quase-monopólio ${ }^{8}$.

Tomando por base os critérios definidos no âmbito do MEC, reafirmado por documentos oficiais, buscamos entender a dinâmica estabelecida para oferta dos Cursos do PROEJA no Maranhão. Uma primeira observação nos fez constatar que, na grande maioria dos Câmpus, os cursos estão assentados no eixo tecnológico Desenvolvimento Educacional e Social, conforme tabela abaixo:

Tabela 2 - Eixos Tecnológicos e Cursos ofertados PROEJA

\begin{tabular}{|c|c|c|c|c|c|c|c|}
\hline \multirow{2}{*}{ CAMPUS } & \multirow{2}{*}{ EIXO TECNOLÓGICO } & \multirow{2}{*}{$\begin{array}{l}\text { CURSO MODALIDADE } \\
\text { PROEJA }\end{array}$} & \multicolumn{5}{|c|}{ OFERTA DE VAGAS } \\
\hline & & & 2007 & 2008 & 2009 & 2010 & 2011 \\
\hline \multirow{2}{*}{$\begin{array}{l}\text { MONTE } \\
\text { CASTELO }\end{array}$} & Produção Alimentícia & Química de Alimentos & 40 & & & & \\
\hline & $\begin{array}{l}\text { Controle e Processos } \\
\text { Industriais }\end{array}$ & Eletrotécnica & & & & & 40 \\
\hline \multirow{2}{*}{ MARACANÃ } & Recursos Naturais & Agropecuária & & 40 & 40 & 40 & 40 \\
\hline & Hospitalidade e Lazer & Cozinha & & & 40 & 40 & 40 \\
\hline $\begin{array}{l}\text { CENTRO } \\
\text { HISTÓRICO }\end{array}$ & $\begin{array}{l}\text { Produção Cultural e } \\
\text { Design }\end{array}$ & Artesanato & & & & 40 & 30 \\
\hline CODÓ & Produção Alimentícia & Agroindústria & & & & 35 & 40 \\
\hline \multirow{2}{*}{ SANTA INÊS } & $\begin{array}{l}\text { Desenvolvimento } \\
\text { Educacional e Social }\end{array}$ & Infraestrutura Escolar & & & 40 & 40 & \\
\hline & Gestão de Negócios & Administração & & & & & 40 \\
\hline ZÉ DOCA & $\begin{array}{l}\text { Desenvolvimento } \\
\text { Educacional e Social }\end{array}$ & Secretariado Escolar & 40 & 40 & 40 & 40 & 40 \\
\hline
\end{tabular}




\begin{tabular}{|c|c|c|c|c|c|c|c|}
\hline \multirow{2}{*}{ BURITICUPU } & $\begin{array}{l}\text { Desenvolvimento } \\
\text { Educacional e Social }\end{array}$ & Secretariado Escolar & 40 & 40 & 40 & & \\
\hline & Gestão e Negócios & Vendas & & & & 40 & \\
\hline \multirow{3}{*}{ AÇAILÂNDIA } & $\begin{array}{l}\text { Desenvolvimento } \\
\text { Educacional e Social }\end{array}$ & Alimentação Escolar & & 40 & & & \\
\hline & $\begin{array}{l}\text { Controle e } \\
\text { Processamentos } \\
\text { Industriais } \\
\end{array}$ & Eletromecânica & & & 40 & 40 & \\
\hline & $\begin{array}{l}\text { Meio Ambiente e } \\
\text { Segurança }\end{array}$ & Meio Ambiente & & & & & 40 \\
\hline \multirow{3}{*}{ IMPERATRIZ } & $\begin{array}{l}\text { Desenvolvimento } \\
\text { Educacional e Social }\end{array}$ & Infraestrutura Escolar & & & 40 & & \\
\hline & Infraestrutura & $\begin{array}{l}\text { Construções de Obras } \\
\text { Civis }\end{array}$ & & 40 & & 40 & \\
\hline & Gestão e Negócios & Administração & & & & & 40 \\
\hline \multirow{3}{*}{ ALCÂNTARA } & Recursos Naturais & Agroecologia & & & & 40 & \\
\hline & Hospitalidade e Lazer & Guia de Turismo & & & & & 40 \\
\hline & & & 120 & 200 & 280 & 395 & 390 \\
\hline
\end{tabular}

Fonte: PDI (2009 - 2013), edital n 44 , de 25 de novembro de 2011. Tabela formulada pela pesquisadora.

Observando o quadro de ofertas dos Câmpus da fase da Pré-expansão e dos Câmpus da primeira fase da expansão ${ }^{9}$, convém salientar que todos aqueles referentes à primeira fase, com exceção do Campus Centro Histórico (os outros Câmpus: Buriticupu, Zé Doca, Santa Inês e Açailândia) convergem para oferta educacional no eixo tecnológico Desenvolvimento Educacional e Social. Porém, a oferta educacional não correspondia ao propagado pelos documentos oficiais de que a expansão deveria atender aos arranjos produtivos locais, ou seja, ao eixo produtivo industrial ou comercial. Observando esta contradição que desvia da deliberação oficial da SETEC e do MEC, qual a justificativa para a opção destas ofertas educacional para o segmento de alunos jovens e adultos em idade socialmente irregular?

$\mathrm{Na}$ busca por entender a lógica da expansão em busca da conformação das massas e no controle social em regiões de intenso conflito social com o empresariado ${ }^{10}$, constatou-se que as primeiras opções de oferta dos cursos para a classe trabalhadora buscou amenizar as dificuldades de aprendizagens que os alunos teriam em cursos com grau de complexidade mais elevado e, ao mesmo tempo, determinou aos trabalhadores que sua formação está vinculada à incorporação do trabalho simples para o exercício de atividades laborais que demandam conhecimentos de menor complexidade. A concepção da formação para o exercício do trabalho simples é um imperativo na formação de jovens e adultos trabalhadores. Conforme destaca Marx (2006, p. 66):

O trabalho humano mede-se pelo dispêndio da força de trabalho simples, a qual, a média, todo homem comum, sem educação especial, possui em seu organismo. O trabalho simples médio muda de caráter com os países e estágios da civilização, mas é dado numa determinada sociedade.

Em tal perspectiva de expansão das ofertas educacionais para os trabalhadores é possível destacar, conforme Rummert (2008), que o caráter do trabalho simples, em suas 
diferentes proporções no Brasil, tem como traços fundamentais a distribuição diferencial do conhecimento e a precarização do trabalho, elementos necessários para o fortalecimento do modelo de desenvolvimento desigual e combinado. "Eleva-se, assim, o nível de certificação e no bojo do mesmo processo rebaixa-se o grau de conhecimentos a que tal certificação corresponde" (RUMMERT, 2011, p. 150).

A produção capitalista conforme análise de Marx (2012), desqualifica a maioria dos trabalhadores e cria um pequeno número de trabalhadores altamente qualificados. $\mathrm{O}$ valor da força de trabalho, como de toda mercadoria, é determinado pelo tempo necessário à produção, portanto, também a reprodução desse produto específico é determinado pelo tempo necessário à sua produção ou reprodução.

Marx (2012) demonstra por meio do estudo da Maquinaria como o saber é empregado como força produtiva do capital. O ponto de partida da indústria moderna é a revolução instrumental do trabalho, por meio do emprego da ciência e da tecnologia. Antes da fábrica mecanizada (maquinaria), a manufatura, por meio da divisão social baseada no corpo do trabalhador, deu início ao processo de subsunção real do trabalho ao capital. A maquinaria reifica o corpo do trabalhador. Para trabalhar com máquinas, o trabalhador adapta seu próprio corpo ao movimento uniforme e contínuo automático. O corpo do trabalhador é educado, é reificado pela maquinaria.

O emprego da ciência e da tecnologia na produção ocasiona a separação entre o saber e o trabalhador. A produção do conhecimento empregado na produção

torna-se objeto de um 'novo artesanato' envolvendo artífices e cientistas. A produção capitalista tende, conforme a interpretação de Marx, a desqualificar a maioria dos trabalhadores e a criar um pequeno número de trabalhadores altamente qualificados (BRYAN, 1999, p. 10).

Para Marx (2012, p. 551), a indústria moderna criou a ciência da tecnologia. E a esse respeito, ele declara:
A indústria moderna rasgou o véu que ocultava ao homem seu próprio processo social de produção e que transformava os ramos de produção naturalmente diversos em enigmas, mesmo para aquele que fosse iniciado num deles. Criou a moderna ciência da tecnologia o princípio de considerar em si mesmo cada processo de produção e de decompô-lo, sem levar em conta qualquer intervenção da mão humana, em seus elementos constitutivos. As formas multifárias, aparentemente desconexas e petrificadas do processo social de produção se decompõem em aplicações da ciência conscientemente planejadas e sistematicamente especializadas segundo o efeito útil requerido. A tecnologia descobriu as poucas formas fundamentais do movimento, em que se resolve necessariamente toda a ação produtiva do corpo humano, apesar da variedade dos instrumentos empregados, do mesmo modo que a mecânica nos faz ver, através da grande complicação da maquinaria, a contínua repetição das potências mecânicas simples (MARX, 2012, p. 551, grifos nossos).

Segundo Marx (2012), o capitalista passou a empregar a ciência e a tecnologia, conscientemente planejadas e sistematizadas, para aumentar a eficiência na extração de mais- valia relativa ${ }^{11}$; a base técnica da indústria moderna é revolucionária, ela reifica o corpo do trabalhador. "Exige, por sua natureza, variação do trabalho, isto é, fluidez das funções, mobilidade do trabalhador em todos os sentidos" (MARX, 2012, p. 552). 
$\mathrm{Na}$ análise de Marx (2012), as escolas politécnicas e agronômicas e as escolas profissionais são reflexos desse processo de produção desencadeado pela indústria moderna, no qual "os filhos dos operários recebem algum ensino tecnológico e são iniciados no manejo prático dos diferentes instrumentos de produção" (MARX, 2012).

A extração da mais valia, advinda da redução do tempo de trabalho necessário e da ampliação e intensificação do trabalho excedente, não altera apenas o tempo da produção, mas relaciona-se ao tempo de formação dos trabalhadores. Pois,

[...] o capital, ao reduzir o tempo de trabalho necessário para produção, vai ter que escolher entre ter maior quantidade (mais barata) de trabalho simples ou ter maior quantidade (mais cara) de trabalho complexo. Portanto, haverá uma contradição entre tempo da produção e tempo da formação, da qual surgirão quatro tendências: a) aumento do tempo de trabalho excedente; b) redução do tempo de trabalho necessário; c) aumento do tempo de formação com mais trabalho complexo (mais caro); d) redução do tempo de formação com mais trabalho simples (mais caro) (LIMA, 2012, p. 498)

O aumento da formação com mais trabalho complexo diminui o tempo socialmente necessário para a produção, mas também implica o aumento do tempo socialmente necessário para a formação profissional, produzindo dispêndio maior de custos na reprodução da força de trabalho. Nesta lógica, ocorre a perda de lucro com gasto na formação profissional em trabalho complexo. É assim, conforme destaca Marx (2012), que a produção capitalista desqualifica a maioria dos trabalhadores e cria um pequeno número de trabalhadores altamente qualificados, reduzindo o custo para formação profissional especializada e amplia-se a formação do trabalhador com menor tempo, visando à incorporação ao trabalho simples que demanda menor tempo e custo nos cofres do Estado.

\section{CONSIDERAÇÕES FINAIS}

A política social, aqui analisada por meio de políticas focais para formação dos trabalhadores, na perspectiva de Algebaile (2004, p. 117), cumpre um papel estratégico no conformismo dos segmentos das classes empobrecidas "[...] ao reforçar a idéia de que o Estado garante uma espécie de contra-peso a favor dos menos favorecidos, cria a impressão de alguma igualdade, favorecendo a formação de um certo consenso" em relação às regras que determinam a organização da vida social, política e econômica.

A diversificação das ofertas pela via de trajetórias subordinadas percorridas no interior da escola reflete em processos educacionais de formação aligeirada, que visam compensar a negação do direito a educação de qualidade socialmente referenciada em substituição a políticas focais que buscam fantasiar o preenchimento de lacunas do processo histórico de exclusão social da classe trabalhadora.

A ampliação cada vez mais diversificada de programas de qualificação para os trabalhadores no âmbito dos Institutos Federais, ora com elevação da escolaridade integrada à qualificação profissional, ora apenas com cursos de caráter profissionalizante, apresentam como característica comum a distribuição desigual do saber científico e do saber prático, a redução dos conteúdos e do tempo de escolarização. Nesse sentido, os programas destinados à formação do trabalhador, colaboram, na maioria das vezes para a melhoria da autoestima, elevação da escolaridade e para conferir mudanças no cotidiano da vida, nas relações com as pessoas e com a família. 
As ações atualmente em curso, assentadas, de diferentes formas, na lógica dominante, valorizam e exploram modos de ver, fragmentos de concepção de mundo determinados, propiciando àqueles aos quais se destinam a crença no fato de que suas individualidades estão, finalmente, sendo contempladas (RUMMERT, 2008, p. 197).

A diversificação de ofertas formativas também potencializa a falsa ideia de que há uma relação imediata entre elevação de escolaridade ou formação profissional e obtenção de emprego e renda. Este discurso atinge, sobretudo, as frações de classe mais vulneráveis e exploradas. Assim, a promessa da escola como entidade integradora ainda é muito usual. Para Lombardi (2006, p. 1), o discurso de que a escola é solução para todos os males da sociedade é recorrente, nasceu com a sociedade capitalista, integrado ao discurso ideológico que atribuiu "à escola um papel central no cuidado com a infância, com a transmissão dos saberes considerados socialmente relevantes, com a formação do cidadão e com a qualificação do trabalhador".

Esta perspectiva sobre o papel da escola remete uma função que ela não cumpre, pois se o atual sistema de produção não consegue gerar emprego e renda para todos, como a instituição escolar conseguirá promover aquilo que o próprio sistema em que ela está inserida não oferece em sua atual fase de acumulação, o toyotismo? A dualidade estrutural de novo tipo cria a fantasia da inclusão social e democratização do acesso à educação de qualidade a todas as frações de classes. Compreender esta dinâmica é fundamental para fortalecer o processo de construção de resistência e luta em defesa de uma educação pública que de fato confira um espaço democrático e privilegiado para formação integral à classe trabalhadora, nos princípios do Trabalho, da Ciência e da Cultura.

A esse respeito, Gramsci (1995) destacou, à sua época, que este novo tipo de escola foi louvada socialmente e apareceu revestida de democracia. Porém, elas são destinadas a perpetuar diferenças que constroem a marca social da escola, a dualidade estrutural. Neste caso, a "multiplicação de tipos de escola profissional, portanto, tende a eternizar as diferenças tradicionais; mas, dado que ela tende, nestas diferenças, a criar estratificações internas, faz nascer a impressão de possuir uma tendência democrática".

\section{Referências}

ALVES, Giovanni. O novo (e precário) mundo do trabalho: reestruturação produtiva e crise do sindicalismo. São Paulo: Boitempo, 2000.

ALVES, Gilberto Luis. A produção da escola pública contemporânea. Campinas: Autores Associados, 2006.

ALGEBAILE, Eveline Bertino. Escola Pública e Pobreza: expansão escolar e formação escolar para pobres no Brasil. Tese de Doutorado, Programa de Pós-Graduação em Educação, Universidade Federal Fluminense, 2004.

ANTUNES, Ricardo. Os sentidos do trabalho: ensaio sobre a afirmação e a negação do trabalho. São Paulo: Boitempo, 2005.

BRASIL. Decreto n. ${ }^{\circ}$ 6.095/2007. Cria a Rede Federal de Educação Profissional, Científica e Tecnológica, e dá outras providências. Diário Oficial da União de 30/12/2008. Brasília, 2008.

Lei n. ${ }^{\circ}$ 11.892, de 29 de dezembro de 2008. Institui a Rede Federal de Educação Profissional, Científica e Tecnológica, e dá outras providências. Diário Oficial da União de 30/12/2008. Brasília, 2008.

Ministério da Educação. Plano de Expansão da Educação Profissional.

Brasília, SETEC, 2005. Disponível em: 
http://portal.mec.gov.br/setec/arquivos/pdf/expansao_plano.pdf . Acesso em: 24 de Jul. 2011.

.Termo de Referência para Política Nacional de Apoio ao Desenvolvimento dos Arranjos Produtivos Locais. Versão para discussão nos GT Interministerial. Versão Final, 16 de abril de 2004. Disponível em:

http://www.desenvolvimento.gov.br/arquivos/dwnl_1289322946.pdf. Acesso em: 17 fevereiro: 2013.

BRANDÃO, Marise. O governo Lula e a chamada educação profissional tecnológica. Revista RETTA. Revista RETTA. Dossiê: Reforma do Ensino Técnico e Tecnológico no Brasil. Rio de Janeiro. v. 1. $\mathrm{n}^{\mathbf{o}}$. 1, jan. jun. ano 2010.

. Da arte do ofício à ciência da indústria: A conformação do capitalismo industrial no Brasil vista através da educação profissional. Vol. 25 - Número 3 -

Setembro/Dezembro 1999 Disponível em: http://www.senac.br/BTS/253/boltec253b.htm. Acesso em: 10 de setembro de 2012.

BRYAN, Newton Antonio Paciulli. Educação, trabalho e tecnologia em Marx. Revista Educação \& Tecnologia n. 1, ano 2011. Disponível em:

$\langle$ http://revistas.utfpr.edu.br/pb/index.php/revedutec-ct/article/view/1010>. Acesso em: 03 nov. 2012.

CUNHA, Luis Antônio. O ensino de ofícios artesanais e manufatureiros no Brasil escravocrata. São Paulo: Unesp, Brasília: Flacso, 2005a.

ERBER, Stefano Fabio. Eficiência coletiva em arranjos produtivos locais industriais: comentando o conceito. Nova Economia, v. 18, n.1, p 11-32, Belo Horizonte, jan.abr. de 2008. Disponível em: http://www.simi.org.br/biblioteca/exibir/4699. Acesso $17 \mathrm{de}$ fevereiro de 2013.

FERNANDES, Florestan. Sociedade de classes e subdesenvolvimento. São Paulo, Ed. Global, 2008.

FRANCO, Maria Ciavatta. Fábula da nova República: Criação de duzentas escolas técnicas. In.: Caderno CEDES. O Ensino de $2^{\circ}$ grau: Trabalho e educação em debate. Ed. Cortez, São Paulo: 1988 n. ${ }^{\circ}$ 20, p. 36-47.

FRIGOTTO, Gaudêncio. A relação da educação profissional e tecnológica com a universalização da educação básica In: Revista Educação e Sociedade, Campinas, vol. 28, n. 100 - Especial p. 1129-1152, out. 2007. Disponível em http://www.cedes.unicamp.br. Acesso em 17 de abril de 2014.

FILGUEIRAS, Luiz et al. Modelo liberal-periférico e bloco de poder: política e dinâmica macroeconômica nos governos Lula In: Os anos Lula: contribuições para um balanço crítico 2003-2010. Rio de Janeiro, Editora Garamond, 2010.

FONSECA, Marília. O Banco Mundial e a justiça social no terceiro mundo. $19^{a}$ ANPED, 1996.

FONTES, Virgínia. O Brasil e o capital-imperialismo: Teoria e história. Rio de Janeiro: Ed. UFRJ, 2012.

GENTILI, Pablo. Educar para o desemprego: A desintegração da promessa integradora In: FRIGOTTO, Gaudêncio (org.). Educação e Crise do trabalho: perspectivas de final de século. Petrópolis, RJ. Ed. Vozes, 1998. 
GERMANO, José Willington. Estado militar e educação no Brasil (1964-1985). São Paulo: Cortez, 1993.

GRAMSCI, A. Os intelectuais e a organização da cultura. Tradução: Carlos Nelson Coutinho. $9^{a}$ ed. Rio de Janeiro, Ed. Civilização Brasileira, 1995.

HORA, Lícia Cristina Araújo da. A formação dos trabalhadores na rota dos trilhos: o PROEJA nos municípios de Açailândia e Buriticupu. 2013. Dissertação (Mestrado em Educação) - Universidade Federal Fluminense, Niterói, 2013.

. A formação de jovens e adultos trabalhadores sob controle dos empresários: o caso do Proeja no maranhão. Eja em Debate, Florianópolis, v. 3, n. 4, p. 129-147, jul. 2014.

KUENZER, Acácia Zeneida. A reforma do ensino técnico no Brasil e suas consequências. In: FERRETTI, Celso; SILVA JÚNIOR, João dos Reis \& OLIVEIRA, Maria Rita (orgs.). Trabalho, formação e currículo: Para onde vai a escola? São Paulo: Xamã, 1999. pp. 121-140.

LEHER, Roberto. Um novo senhor da educação? A política educacional do Banco Mundial para a periferia do capitalismo. Revista Outubro. n 3, 1999.

LIMA, Marcelo. Problemas da Educação Profissional do governo Dilma: PRONATEC, PNE e DCEMs In: RBPAE - v. 28, n. 2, p. 495-513 mai/ago. 2012 Disponível em: http://seer.ufrgs.br/index.php/rbpae/article/view/37418/24159. Acesso: 02 de setembro de 2014.

MANCEBO, Dayse. Subjetividade Docente. Trabalho Docente na Educação Básica Dicionário Verbetes. Disponível em:

http://trabalhodocente.net.br/index.php?pg=dicionario-verbetes. Acesso: 07 dez. 2013.

MARX, Karl. O capital: crítica a economia política: livro I. Tradução Reginaldo Sant`Anna. 30. ed. Rio de Janeiro: Civilização Brasileira, 2012.

MANACORDA, M. A. O Principio educativo em Gramsci. Porto Alegre: Artes Médicas, 1990.

MORAIS, Marli Alcântara Ferreira. O tempo dos trabalhadores nos trilhos do capital: o processo de aceleração temporal na Companhia Vale do Rio Doce. Tese (Doutorado em Políticas Públicas), Programa de Pós-Graduação em Políticas Públicas, Universidade Federal do Maranhão, 2007.

NETTO, José Paulo. Uma face contemporânea da barbárie In.: Anais II Encontro Internacional "Civilização ou Barbárie", Serpa, 30-31 de outubro/1 de novembro de 2010.

NETTO, José Paulo, BRAZ, Marcelo. 7. ed. Economia Política: uma introdução crítica. São Paulo: Cortez, 2011.

NEVES, Lúcia Maria W. Brasil 2000: A nova divisão de trabalho na Educação. $2^{a}$ ed. São Paulo, ed. Xamã, 2000.

OLIVEIRA, Francisco de. Crítica à razão dualista: o ornitorrinco. São Paulo: Boitempo, 2003.

PACHECO, Eliezer. Os Institutos Federais: Uma revolução na Educação Profissional e Tecnológica. Natal, Ed. IFRN, 2010.

PLANO DE DESENVOLVIMENTO INSTITUCIONAL - PDI 2009 - 2013. Maranhão, jun. 2009.

RELATÓRIO RESPONSABILIDADE SOCIAL DAS EMPRESAS SIDERÚRGICAS NA CADEIA PRODUTIVA DO FERRO-GUSA NA REGIÃO DE CARAJÁS: OS 


\section{PRODUTORES DE CARVÃO VEGETAL INSTITUTO OBSERVATÓRIO SOCIAL.}

Rio de Janeiro, 2006. Disponível em:

$<$ http://www.carvaocidadao.org.br/media/uploads_media/Responsabiliadade_Social_das_E mpresas_Siderrgicas.pdf>. Acesso em: 05 ago. 2012.

RELATOS DO ENCONTRO REGIONAL DOS ATINGIDOS PELA VALE (PA, MA, TO). 13 e 14 de junho de 2011. Disponível em: 〈http://www.observatorio.ufma.br/noticias /mostra_noticias.php?id=5609>. Acesso em: 10 jan. 2013.

RODRIGUES, José dos Santos. O moderno príncipe industrial: O pensamento moderno da Confederação Nacional da Indústria. Tese Doutorado. Universidade Estadual de Campinas, Faculdade de Educação, 1997.

ROSAR, Maria de Fátima Félix, CABRAL, Maria Regina Martins (org.). Ensino Médio e Educação Profissional no Maranhão: delineando o perfil e ressignificando os cursos com a participação dos jovens. São Luís, ed. Central dos Livros, 2004.

RUMMERT, Sonia Maria. Notas sobre o pensamento de Antonio Gramsci - Contribuições à reflexão acerca da temática educacional. Revista de Ciências da Educação - Sísifo. jan./abr. 04 (p. 11-52). Universidade de Lisboa, 2007.

RUMMERT, Sonia Maria. Educação de jovens e adultos trabalhadores no Brasil atual: do simulacro à emancipação In: Revista Perspectiva, Florianópolis, v. 26, n. 1, p. 175-208, 2008. Disponível em: <http//www.perspectiva.ufsc.br>. Acesso em: 25 de agosto de 2010. RUMMERT, Sonia; ALGEBAILE, Eveline; VENTURA, Jaqueline. Educação e formação humana no cenário de integração subalterna no capital-imperialismo In: SILVA, Mariléia Maria da; EVANGELISTA, Olinda; QUARTIERO, Elisa Maria. (Org.). Jovens, Trabalho e Educação: A conexão subordinada de formação para o capital. $1^{a}$ Ed. Campinas: Mercado das Letras, 2012, v. 1, p. 15-70.

\footnotetext{
${ }^{1}$ Mestre em Educação pela UFF, Professora de Educação do IFMA, pesquisadora do HISTEDBR GT MA e do Grupo EJA Trabalhadores da UFF.

\begin{abstract}
${ }^{2} \mathrm{O}$ "homem massa" não possui clara consciência do significado de sua própria ação e não avalia criticamente sua forma de participação no processo histórico; pensa de modo desagregado e assistemático, assumindo como sua uma concepção de mundo em que predominam elementos da concepção de mundo imposta pela classe que detém o poder, o que o impede de agir de modo crítico e coerente [...]. A consciência fragmentada do homem-massa, leva-o, como já referido, a possuir uma concepção de mundo imposta pelo mundo exterior e assumida sem crítica [...] (RUMMERT, 2007, p. 15-16).
\end{abstract}

${ }^{3}$ Os Institutos Federais de Educação, Ciência e Tecnologia (IFETs), criados a partir da Lei n. ${ }^{\circ}$ 11.892/2008, deram início a um novo projeto de instituição dentro da Rede Federal, congregando Escolas Técnicas Federais (ETFs), Escolas Agrotécnicas Federais (EAFs), Escolas Técnicas Vinculadas a Universidades Federais (EVs) e Centros Federais de Educação Tecnológica (CEFETs). Esta Lei também institui a Rede Federal de Educação Tecnológica Profissional, Científica e Tecnológica.

${ }^{4}$ Expressão utilizada no artigo de Rummert, Algebaile, Ventura (2012).

${ }^{5}$ Siglas da coluna parcerias: Centros de Capacitação Tecnológica do Maranhão (CETECMAs); Secretaria de Educação Continuada, Alfabetização, Diversidade e Inclusão (SECADI); Secretaria de Educação Superior (SESU); Coordenação de Aperfeiçoamento de Pessoal de Nível Superior (CAPES); Secretaria de Estado de Educação do Maranhão (SEDUC).

${ }^{6}$ BPC - Benefício de Prestação Continuada.

${ }^{7}$ Para Gramsci, Estado ampliado significa maior convencimento, mas não elimina a coerção. Seu momento predominantemente consensual ocorre por intermédio da sociedade civil - aparelhos privados de hegemonia. 
Disseminam-se entidades associativas que formulam, educam e preparam seus integrantes para a defesa de determinadas posições sociais e para uma certa sociabilidade (Virgínia Fontes, Dicionário da Educação Profissional, 2009).

8 No artigo de Vasconcelos; Cyrino (2000), Vantagem competitiva: os modelos teóricos atuais e a convergência entre estratégia e teoria organizacional, consta a análise das quatro abordagens teóricas citadas no texto.

${ }^{9}$ O Campus Alcântara iniciou suas atividades administrativas no ano de 2008; no entanto, na época era um Núcleo Avançado de Alcântara. Somente no ano de 2010 recebe o status de Campus.

${ }^{10}$ No ano de 2014 foi realizado o Seminário 30 aos Carajás. Neste evento reuniu comunidades de várias regiões do Brasil e representantes de alguns países vítimas de impactos sociais e ambientais produzidos pela mineradora Vale. Atualmente as comunidades atingidas pela vale estão articuladas em Rede conhecida como Atingidos pela Vale. Alguns dos impactos vividos pelos atingidos pela vale podem ser encontrados em relatórios produzidos dos eventos de articulação desta Rede.

11 A SEMTEC no governo de Luís Inácio Lula da Silva passou a se chamar Secretaria de Educação Tecnológica - SETEC.

Recebido: jun/2015 $\quad$ Aprovado: jul/2015 